\title{
A Comparison of Dietary Practices At or En Route to School between Elementary and
}

\section{Secondary School Students in Vancouver, Canada}

Cayley E Velazquez ${ }^{1 *}$, Jennifer L Black ${ }^{1}$, Jean-Michel Billette ${ }^{2}$, Naseam Ahmadi ${ }^{1}$, Gwen E Chapman $^{1}$

${ }^{1}$ Faculty of Land and Food Systems, University of British Columbia, Vancouver, BC, Canada;

${ }^{2}$ Statistics Canada, Ottawa, ON, Canada

Submitted 1 November 2013, Accepted 12 February 2015

\begin{abstract}
Background: There is evidence that dietary quality declines as children age in North America, but few studies have explored whether food environment exposures in secondary schools as opposed to elementary schools are associated with changes in students' school-day food choices.

Methods: This study examined differences in dietary practices (at or en route to and/or from school) between students in their last years of elementary school (grades 5-7) and first year of secondary school (grade 8) in Vancouver, Canada, controlling for socio-demographic characteristics and school-level socio-economic status. Demographic characteristics and dietary data were collected through a cross-sectional survey ( $\mathrm{n}=950$ from 26 schools) and combined with school-level socioeconomic data derived from the 2006 Canadian Census.

Results: Multi-level logistic regression analyses indicated that secondary school students were significantly more likely to report daily consumption of fast foods (Odds Ratio (OR)=1.92; 95\% Confidence Interval $(\mathrm{CI})=1.18-3.12$ ) and minimally nutritious packaged snacks (e.g., candy or chocolate bars $)(\mathrm{OR}=1.60 ; \mathrm{CI}=1.05-2.45)$, and to report regular purchases from off-campus
\end{abstract}

\footnotetext{
*Corresponding author; Email: cayley.velazquez@ubc.ca

This is an un-copyedited author manuscript that was accepted for publication. Cayley E Velazquez, Jennifer L Black, Jean-Michel Billette, Naseam Ahmadi, and Gwen E Chapman. (2015) A Comparison of Dietary Practices At or En Route to School between Elementary and Secondary School Students in Vancouver, Canada. Journal of the Academy of Nutrition and Dietetics, 115(8), 1308-1317. Epub: 29 April 2015. PubMed PMID: 25935568, copyright

Elsevier. The final version of record, copyedited by Elsevier, can be found at: http://dx.doi.org/10.1016/j.jand.2015.02.030
} 
retailers $(\mathrm{OR}=1.63 ; \mathrm{CI}=1.10-2.42)$. Gender, food insecurity, lower acculturation to Canada, and access to more weekly spending money were associated with nutritionally-poor practices. Students attending schools drawing from lower income neighborhoods were also significantly more likely to consume fast foods and packaged snacks daily. The majority of students sampled did not report consuming healthy foods such as fruit and vegetables daily at or en route to and/or from school. Intake of fruit, vegetables and low fat milk did not differ significantly between elementary and secondary school students.

Conclusions: Findings suggest that research and intervention strategies should address modifiable school-level exposures and policies to improve dietary practices for both elementary and secondary school-aged youth, while at the same time, addressing socio-cultural factors associated with eating behavior.

Keywords: Dietary Intake, Food Purchasing, Youth, School health, Socioeconomic status

\section{Introduction}

Like American youth, most Canadian school-children and adolescents do not meet national dietary recommendations, ${ }^{1,2,3}$ and the prevalence of adverse nutrition-related outcomes including obesity and type 2 diabetes is rising. ${ }^{4,5}$ Consequently, improving the eating habits and nutritional health of children and adolescents is a priority area for international public health efforts. Recent initiatives including the Institute of Medicine's strategies for enhancing obesity prevention ${ }^{6}$ and the World Health Organization's Health Promoting Schools framework and Nutrition Friendly Schools initiatives ${ }^{7}$ now emphasize the importance of schools as key institutions for nurturing healthy habits. Yet, in-depth understanding is still lacking about the factors that shape food practices in schools where children and adolescents spend a substantial portion of their time.

To inform emerging school-based intervention strategies, a small but growing number of researchers have begun investigating whether and how characteristics of school food environments impact dietary behaviors. ${ }^{8-14}$ Several studies have examined associations between characteristics 
of the school environment and obesity outcomes, or impacts of specific school-based interventions. However, few have carefully evaluated whether nutrition-related outcomes differ after students transition from elementary school to secondary school, where they may have more autonomy over food choices; or how differences in these two contexts shape specific dietary practices. Moreover, most studies have been conducted in the United States (U.S) and may not be generalizable to other developed countries, including Canada where the school food setting differs.

Unlike the U.S., Canada does not have a nationally funded school lunch program. And while school environment research is in its infancy in Canada, there is evidence that food environment exposures differ between elementary and secondary contexts. ${ }^{15}$ In Canadian schools, foods are generally available from a variety of sources including cafeterias (some of which include subsidized meal programs for vulnerable students), vending machines, school stores, fundraisers (e.g. pizza lunches, bake sales) and special food days or food provided or sold by parents or community groups, which vary widely among and between elementary and secondary schools. For instance, in the province of British Columbia (BC), Canada's westernmost province, $82 \%$ of elementary schools report hosting food-based fundraisers in the last month compared with only $39 \%$ of secondary schools. ${ }^{15}$ On the other hand, vending machines are common in secondary schools, but are found in less than $2 \%$ of BC elementary schools. ${ }^{15}$

School food environments are thought to be promising settings for nutrition-related programs with emerging research suggesting that school-based interventions can improve dietary quality. ${ }^{8-11}$ Recent school food policy changes proposed in both Canada and the U.S. seek to improve diet-related outcomes for youth. ${ }^{16-19}$ In BC, the provincial government has initiated several programs including Action Schools! BC, Sip Smart! BC, Farm to School and the School Fruit and Vegetable Snack Program to improve access to nutritious foods and to reduce exposures to foods of low nutritional quality. ${ }^{20}$ Moreover, revised province-wide guidelines now restrict the sale of foods and beverages with poor nutritional quality across all settings where foods are sold 
inside schools including cafeterias, vending machines, fundraising efforts and school events. ${ }^{21,22}$ Despite these efforts, little is known about whether and why students' dietary practices differ across educational settings. Thus, identifying school-level exposures that influence dietary behaviors might help to inform nutrition intervention strategies and food policy changes.

Socio-cultural factors including gender, socio-economic status and food security are also established determinants of dietary practices. ${ }^{23-26}$ For example, dietary practices and concerns related to eating and body image differ by gender ${ }^{27,28}$ and boys report greater energy and nutrient intakes than girls. Overall, boys choose foods both higher (e.g. grains, milk products, and meat/alternatives) and lower (e.g. soft drinks, salty snacks and French fries) in nutritional quality. ${ }^{29}$ Further, students from low-income and food insecure households may consume fewer milk products, ${ }^{30,31}$ fruit, and vegetables, ${ }^{30}$ and more fast food ${ }^{32}$ and sugar-sweetened beverages ${ }^{31,33}$ than food secure youth. Additionally, while research from the U.S. has examined differences in dietary intake among youth who are more or less acculturated, ${ }^{34}$ relatively little is known about whether children who immigrate to Canada acquire or reject the dietary norms encountered at school.

There is also growing interest from researchers with regard to the roles of socioeconomic conditions within and surrounding schools and their neighbourhoods in shaping nutrition-related outcomes. $^{35,36}$ At least two Canadian studies of youth have reported positive associations between area-level socioeconomic status (SES) and intake of fruit, vegetables and fiber, and negative associations with intake of minimally nutritious choices. ${ }^{37,38}$ There is some evidence from both the U.S. and Canada that secondary schools and schools in neighborhoods characterized by lower SES are more likely to have access to nearby fast food vendors. ${ }^{39-41}$ While the mechanisms through which area-level SES impact students' diets remain unclear, examining and controlling for differences in school-SES may help clarify understandings about the broader contextual factors associated with dietary practices. 
Clearly, the multiple levels of influence on food choice are complex. More evidence is needed to understand the dynamics of school-day dietary intake and food purchases and whether varied policies and food environment exposures in secondary schools are associated with the declining dietary quality reported for older children. The primary objective of this study was to assess whether dietary practices at or en route to/from school differ among students in their final years of elementary school and first year of secondary school in Vancouver, Canada.

\section{Methods}

This study draws on cross-sectional data from the 2012 Individual Eating Assessment Tool (IEAT) survey. Sampling was based on a two-stage cluster approach described previously, ${ }^{33}$ which sampled schools from all six geographic sectors within the Vancouver Board of Education, ${ }^{22}$ with a school-level participation rate of $74 \%$. Classes were recruited through invitations to teachers and school administrators and all students in the selected classes were invited to participate.

The survey was completed on-line, in-class by 964 students from 20 elementary schools (grades 5-7) and 6 secondary schools (grade 8), between March-June 2012 (student-level response rate $=81 \%$ ). The sample included socio-demographically diverse public school students in their last year(s) of elementary school or first year of secondary school. The survey protocol was informed by previous studies with adolescents ${ }^{42,43,44}$ and was pilot tested with 10 content experts and 54 students from grades 7-12 to ensure face and content validity. A field test was then carried out in one grade 6/7 split classroom to further ensure comprehension of core questions and feasibility in the school context. All protocols were approved by the Behavioural Research Ethics Board at the University of British Columbia and the Vancouver Board of Education. Active student assent was required to commence in-class surveys and consent forms were sent home to parents who could indicate dissent to their child's participation by returning signed forms.

\section{Dietary Practices, Dependent Variables}


Food frequency questions were informed by a tool used previously with Canadian students in grades $5-12,{ }^{45}$ adapted to focus on usual intake of foods consumed at or en route to/from school (“on school-days"). Questions asked about typical intake of food or beverage items over the past 30 days to capture usual dietary practices, including some which are typically reported only sporadically over the course of a month. Dependent variables were selected to represent categories of foods recommended or discouraged by regional (Province of BC) and national guidelines $^{22,46}$ and that are at the focus of recent policy debates and school-health interventions. Consumption of minimally nutritious foods included: 1) typical fast foods, 2) sugar-sweetened beverages and 3) packaged snacks. Intake of nutritious foods included: 1) fruit, 2) vegetables, 3) whole grains, and 4) low-fat milk (see table 1 for specific items included in each category). Response options were: Never, once/month, 2-3 times/month, once/week, 2-4 times/week, once/day (every school day), and 2+ times/day (every school day, multiple times). For each food category, students' intake was defined as daily or more (versus less than daily) on school days to represent broad adherence to recommendations about key foods of interest. Intake was coded as daily if responses to questions in a given category summed to 5 times per week or more.

Off-campus food purchasing behavior assessed students' typical frequency of procurement from fast food/take out restaurants, food courts, convenience stores and coffee shops in a typical month at or en route to/from school. Students who purchased food off-campus weekly or more were considered habitual/frequent purchasers, similar to other studies. ${ }^{47,48}$

\section{Independent Variables}

Students in their last year of elementary school, or who shared a "split classroom" with grade 7 students (which included students in grades 5 and/or 6 in the same classes as grade 7 students) were compared to those in their first year of secondary school (grade 8). Gender identity was reported as male/female. A proxy measure for level of acculturation (high, medium or low) was informed by previous public health literature ${ }^{49,50}$ and was assessed using language spoken at 
home (English/other), country of birth (Canada/other), and parents'/guardians' country of birth (Canada/other). Students who spoke another language at home, were born outside Canada, and whose parents/guardians were born outside Canada were classified as least-acculturated, whereas students using English at home, born in Canada, and with Canadian born parents/guardians were classified as most acculturated. Household food insecurity was measured with five questions developed by the United States Department of Agriculture (USDA), used previously in national surveys in the U.S. and Canada. ${ }^{51,52,53}$ An example item was, "In the past 12 months, were you hungry but didn't eat because your family didn't have enough food? never/sometimes/a lot," Based on USDA coding recommendations, ${ }^{53}$ individual items were recoded as never $=0$ versus sometimes/a lot=1, and then summed. A dichotomous food security variable was created (total score of $0-1=$ food secure; $\geq 2$ =food insecure). Participants who brought lunch from home every school-day were compared to all other students to examine the role of routinely packing a lunch

from home. Based on work from Darling et al, ${ }^{54}$ students' weekly spending money was examined in $\$ 10$ increments (none/>\$0-10/>\$10-20/>\$20).

School-level SES was estimated using a school's median income derived from median family income estimates pertaining to students' neighborhoods of residence using Census dissemination area values from the 2006 Canadian Census. This variable was constructed by the BC Ministry of Education and was weighted by the proportion of students per school living in each neighborhood in 2006/2007. ${ }^{55}$

\section{Data Analysis}

Descriptive statistics included means, standard deviations (SD), and frequencies. Unadjusted associations between categorical variables were assessed using Pearson's chi-square tests (statistical significance defined as $\mathrm{p} \leq 0.05$ ). Multi-level logistic regression models were initially tested with no covariates (null models) for each dependent variable, all of which demonstrated significant variation between schools at the $\mathrm{p} \leq 0.05$ level, with the exception of 
minimally nutritious packaged snacks ( $\mathrm{p}=0.06$ : borderline significant $)$ and whole grains $(\mathrm{p}=0.38)$. Models then assessed associations between school type (elementary/secondary) and food practice variables, with all other covariates of interest (i.e. gender, acculturation, food security, lunch from home, access to spending money, school socio-economic status) entered sequentially into models and serving primarily as control variables. Findings from exploratory bivariate analyses of factors associated with daily fast food intake (not shown), and a literature review of potential correlates of school-day dietary choices that may confound the associations between school type and dietary choices, informed the decision to include the variables reported in final models (Tables 2 and 3 ). The magnitude of associations between independent and dependent variables was assessed using adjusted odds ratios (OR) and $95 \%$ confidence intervals (CI), generated by exponentiating the coefficients and CIs from multilevel logistic regression models.

There were 950 students in the final analytic sample. Fourteen completed surveys were excluded due to inappropriate comments on open ended questions. Missing data (range: 1.2\%$33.7 \%$ ) for acculturation, food insecurity, packed lunches, and spending money were imputed with 10 sets of multiple imputations by chained equations. ${ }^{56}$ Stata (version 12, 2011, StataCorp LP) was used for all analyses.

\section{Results and Discussion}

Approximately $75 \%$ of participants were elementary school students (mean age $=12.1 \mathrm{y}$, standard deviation $(\mathrm{SD})=0.68)$. Secondary school students were slightly older, with a mean age of 13.4 years $(\mathrm{SD}=0.51)$. While $66.7 \%$ of students spoke English at home and $75.6 \%$ were Canadian-born, only $22.2 \%$ had both parents/guardians born in Canada. Nearly $16 \%$ reported experiencing food insecurity in the last 12 months (Table 1).

The proportion of key intake variables reported by students as being consumed daily (Table 1) included: fast food items (17.2\%), sugar-sweetened beverages (31.4\%), packaged snacks (20.3\%), fruit (49.6\%), vegetables (42.3\%), whole grains (34.7\%), and low-fat milk (46.3\%). 
Thirty-six percent of students reported purchasing food off-campus each week. There were few significant differences in the intake of nutritious foods between secondary and elementary students. However, in adjusted models, secondary students were significantly more likely to report three out of four of the habitual minimally nutritious dietary practices (Table 2).

Secondary students were nearly twice as likely to consume fast foods daily $(\mathrm{OR}=1.92$; CI $=1.18-3.12)$, and had significantly higher odds of daily packaged snack intake $(\mathrm{OR}=1.60 ; \mathrm{CI}=1.05$ 2.45) and weekly off-campus food purchasing ( $\mathrm{OR}=1.63 ; \mathrm{CI}=1.10-2.42)$ compared to elementary students in adjusted models. We did not examine specific school food environment characteristics in this study, however, in Vancouver, secondary students generally have more opportunities to purchase food inside schools at cafeterias, school stores and vending machines, which are seldom available at the elementary level. ${ }^{15}$ Secondary students may also travel farther distances to school and are more often allowed off-campus during the day. Thus, secondary students likely had more access to vendors selling fast foods and snacks (e.g., potato chips and chocolate bars) than elementary students who might only be offered these foods on occasional theme days, fundraising events or if granted permission to leave campus during lunch.

In adjusted models, gender, food insecurity, and lower acculturation to Canada were independently associated with nutritionally-poor dietary practices. Boys were significantly more likely than girls to consume fast food $(\mathrm{OR}=1.99 ; \mathrm{CI}=1.32-2.29)$ and sugar-sweetened beverages daily $(\mathrm{OR}=1.74 ; \mathrm{CI}=1.27-2.38)$, similar to previous findings. ${ }^{57,58}$ Adolescent boys have higher caloric requirements, ${ }^{59}$ potentially contributing to increased food intake overall. ${ }^{60}$ At the same time, dieting is a relatively common practice among adolescent girls, ${ }^{60}$ which could result in efforts to limit choices perceived as fattening, ${ }^{61}$ such as soda or fast food.

Food insecure students were significantly more likely to consume fast foods daily $(\mathrm{OR}=1.83 ; \mathrm{CI}=1.07-3.14)$. Previous research suggests that food insecure families prioritize price ${ }^{62}$ opting for affordable, filling meals, which could promote intake of foods with lower dietary 
quality. ${ }^{63}$ Students who were least acculturated to Canada also had substantially higher odds of consuming fast food items daily $(\mathrm{OR}=6.17 ; \mathrm{CI}=2.84-13.39)$, a result contrary to previous work where greater acculturation was associated with higher frequency of fast food consumption. ${ }^{64}$ Perhaps least acculturated youth chose fast food to model what they perceive as typical North American dietary choices. ${ }^{65}$

Lunch from home and access to spending money were also associated with school-day choices. While students who brought lunch from home daily had lower odds of purchasing food off-campus $(\mathrm{OR}=0.59 ; \mathrm{CI}=0.43-0.82)$, they were more likely to consume minimally nutritious snacks daily $(\mathrm{OR}=1.77 ; \mathrm{CI}=1.21-2.58)$. For these students, packaged snacks may represent "treats" packed in lunches or items purchased during the day. These findings suggest that it may be important to include parents as part of nutrition interventions because they can be important gatekeepers regarding the quality of packed lunches and, may have influence over students' discretionary spending.

Secondary school students more commonly reported access to higher amounts of spending money than their elementary school peers. Consistent with findings from Darling et al, ${ }^{54}$ students with $>\$ 20 /$ week of spending money were nearly 3-times more likely to consume fast foods $(\mathrm{OR}=2.73 ; \mathrm{CI}=1.17-6.34)$ and had higher odds of regularly buying food off-campus. However, even smaller amounts of spending money (>\$10-\$20/week) were associated with increased likelihood of off-campus food procurement. Access to spending money appears more relevant for influencing less nutritious food purchases than it does for healthful choices such as fruit and vegetables.

Dietary practices were also associated with school-level SES, in that students attending schools drawing from higher-income neighborhoods were less likely to consume fast foods $(\mathrm{OR}=0.75 ; \mathrm{CI}=0.62-0.91)$ and minimally nutritious snacks daily $(\mathrm{OR}=0.79 ; \mathrm{CI}=0.67-0.94)$. These findings are similar to previous studies, where area-level SES was negatively associated with 
intake of minimally nutritious choices, for example, items containing added sugar. ${ }^{37,38}$ After adjusting for other covariates, between-school variance was no longer significant when school income was added to models predicting fast food and snack intake. The lack of significance suggests that for these variables, differences across schools were related to socio-economic differences between schools (or other variables captured by school-level SES). These findings may be the result of lower-income neighborhoods having a higher presence of fast food outlets near schools ${ }^{66,67}$ or unmeasured differences in social norms, school food programs, policies, or environments, or other factors that vary with school SES, which require more attention from researchers.

After controlling for several key student-level demographic factors and school-level SES, secondary school students were consistently more likely to report regular intake of nutritionally poor foods. While previous research suggests that consumption of healthy foods decreases as children age ${ }^{68}$ no significant differences in the intake for fruit, vegetables and low-fat milk between elementary and secondary students were reported. Given that students in this sample were all quite similar in age, this finding may imply that differences in school food exposure in the first year of secondary school alone are not sufficient for shaping the declining intake of nutritious foods, that school-day intake declines more slowly with age than dietary quality reported through the day or that trends among Vancouver students differ from those in previous studies. Students in grades 5-8 are unlikely the primary purchasers of fresh foods for their households, and over three quarters of secondary students in this sample reported at least occasionally (i.e. weekly or more) bringing a packed lunch to school. Hence, parents likely remain key gatekeepers to a healthy diet for youth in this age group.

More than half the sample, regardless of grade-level, did not consume fruit or vegetables daily on school days, and the likelihood of regular intake did not differ significantly by gender, acculturation, food insecurity, bringing lunches from home or access to spending money. Also 
contrary to previous findings, ${ }^{37}$ school-level SES was not significantly associated with nutritious choices. Even after adjusting for all covariates, intake of nutritious items varied across schools, suggesting that other factors not examined here still influence the consumption of healthy schoolday choices. Recent evidence suggests that friends exhibit comparable intakes of vegetables, whole grains and dairy products. ${ }^{69}$ Examining social influences, including peer and parental influences, ${ }^{70}$ would be valuable next steps for research.

Strengths of this study include the socio-demographically diverse sample, composed of nearly one-third of Vancouver's public schools. In Vancouver, school food environments are undergoing change following new school nutrition guidelines mandated by the Province of BC, and are the subject of growing interest from the Board of Education, city government and local university and community stakeholders interested in food system issues. ${ }^{71,72}$ This study provides an understanding of student dietary practices in 2012. Future research may consider using schoolday specific food frequency questions, in conjunction with other dietary intake data collection methods to distinguish between items consumed at or en route to school and other locations. This approach has not been used by most school-focused nutrition studies. In future applications, such insight could help determine the relative contribution of foods available at school to overall dietary intake.

Future studies are however needed to further refine and validate feasible measures that specifically assess school-day dietary intake, and limitations of this study's measures and design should be considered. Notably, the current data cannot be extrapolated to estimate full-day or weekend dietary intake, and additional validation work is needed to ensure that the food frequency tool used here adequately captures usual school-day intake. Further work is needed to examine whether the quality of school-day dietary intake is representative of overall dietary quality. It is possible that dietary quality at school does not provide a complete picture of overall dietary quality. Student self-report of dietary intake may be subject to under- or over-reporting, and 
contain some missing values. ${ }^{73}$ Estimates may be further misreported by the youngest students in this sample. ${ }^{74,75}$ We did not examine specific features of school food environments and these findings may not be generalizable for students outside of Vancouver or in private schools.

\section{Conclusions}

In this study, no differences in daily intake of healthy foods such as fruit, vegetables, or low-fat milk were reported at school or en route to/from school between elementary and secondary school students. However, students attending secondary school were significantly more likely than elementary school students to regularly choose unhealthy foods such as fast foods and minimally nutritious snacks. Results further suggested that students with increased access to spending money are more likely to consume foods with minimal nutritional value. Since secondary students have more access to spending money and opportunities to make independent food purchases, future research in Canada is needed to evaluate emerging interventions aimed at making healthy choices the easy choices for these students. School-based nutrition interventions targeting food insecure students and new immigrants are also necessary, and should consider the gendered nature of students' food practices. Future research is needed to more closely examine potentially modifiable contextual factors and policies that shape dietary differences between elementary and secondary school students and schools in diverse neighborhoods, while addressing student-level factors associated with eating behavior.

\section{References}

1. Health Canada. Canadian Community Health Survey, Cycle 2.2, Nutrition - Nutrient Intakes From Food: Provincial, Regional and National Data Tables. Volumes 1, 2 \& 3. Health Canada Publications; 2004.

2. Health Canada. Do Canadian Adolescents Meet their Nutrition Requirements through Food Intake Alone? Health Canada Publications; 2012. 
3. Veugelers PJ, Fitzgerald AL, Johnston E. Dietary intake and risk factors for poor diet quality among children in Nova Scotia. Can J Public Health. 2005;96(3):212-216.

4. Shields M. Overweight and obesity among youth. Statistics Canada; 2006.

5. Pinhas-Hamiel O, Zeitler P. The global spread of type 2 diabetes mellitus in children and adolescents. J Pediatr. 2005;146(5):693-700.

6. Institute of Medicine. Accelerating Progress in Obesity Prevention: Solving the Weight of the Nation. The National Academies Press; 2012.

7. World Health Organization. What is a health promoting school? http://www.who.int/school_youth_health/gshi/hps/en/index.html. 2012. Accessed August $14,2012$.

8. Arcan C, Kubik MY, Fulkerson JA, Davey C, Story M. Association between food opportunities during the school day and selected dietary behaviors of alternative high school students, Minneapolis/Saint Paul, Minnesota, 2006. Prev Chronic Dis. 2011;8(1):A08.

9. Kubik MY, Lytle LA, Hannan PJ, Perry CL, Story M. The association of the school food environment with dietary behaviors of young adolescents. Am J Public Health. 2003;93(7):1168-1173.

10. Kubik MY, Lytle LA, Story M. Schoolwide food practices are associated with body mass index in middle school students. Arch Pediatr Adolesc Med. 2005;159(12):1111-1114.

11. Wordell D, Daratha K, Mandal B, Bindler R, Butkus SN. Changes in a middle school food environment affect food behavior and food choices. J Acad Nutr Diet. 2012;112(1):137141.

12. Fox MK, Dodd AH, Wilson A, Gleason PM. Association between school food environment and practices and body mass index of US public school children. J Am Diet Assoc. 2009;109(2 Suppl):S108-117. 
13. Nollen NL, Befort CA, Snow P, Daley CM, Ellerbeck EF, Ahluwalia JS. The school food environment and adolescent obesity: qualitative insights from high school principals and food service personnel. Int J Behav Nutr Phys Act. 2007;4:18.

14. Masse LC, de Niet-Fitzgerald JE, Watts AW, Naylor PJ, Saewyc EM. Associations between the school food environment, student consumption and body mass index of Canadian adolescents. Int J Behav Nutr Phys Act. 2014;11(1):29.

15. Rideout K, Levy-Milne R, Martin C, Ostry AS. Food sales outlets, food availability, and the extent of nutrition policy implementation in schools in British Columbia. Can J Public Health. 2007;98(4):246-250.

16. Committee on School Health. Soft Drinks in Schools. Pediatrics. 2004;113(1):152-154.

17. Chriqui JF, Turner L, Taber DR, Chaloupka FJ. Association between district and state policies and US public elementary school competitive food and beverage environments. JAMA pediatrics. 2013;167(8):714-722.

18. Mullally ML, Taylor JP, Kuhle S, et al. A province-wide school nutrition policy and food consumption in elementary school children in Prince Edward Island. Can J Public Health. 2010;101(1):40-43.

19. Watts AW, Masse LC, Naylor PJ. Changes to the school food and physical activity environment after guideline implementation in British Columbia, Canada. Int J Behav Nutr Phys Act. 2014;11:50.

20. Dietitians of Canada. Healthy Eating and Food Security; Promising Stategies for BC http://www.dietitians.ca/Downloadable-Content/Public/Healthy-Eating-and-FoodSecurity-Strategies-BC.aspx. Accessed January 5, 2012.

21. Province of British Columbia. ActNowBC, Healthy Schools. http://www.actnowbc.ca/healthy_living_tip_sheets/healthy_schools. Accessed January 5, 2012. 
22. BC Ministry of Education \& Ministry of Health. Guidelines for Food and Beverage Sales in BC Schools Ministry of Education \& Ministry of Healthly Living and Sport http://www.bced.gov.bc.ca/health/2010_food_guidelines.pdf. Accessed September 9, 2012.

23. Taylor JP, Evers S, McKenna M. Determinants of healthy eating in children and youth. Can J Public Health. 2005;96 Suppl 3:S20-26, S22-29.

24. Tarasuk V, Fitzpatrick S, Ward H. Nutrition inequities in Canada. Appl Physiol Nutr Metab. 2010;35(2):172-179.

25. Ricciuto LE, Tarasuk VS. An examination of income-related disparities in the nutritional quality of food selections among Canadian households from 1986-2001. Soc Sci Med. 2007;64(1):186-198.

26. Riediger ND, Shooshtari S, Moghadasian MH. The Influence of Sociodemographic Factors on Patterns of Fruit and Vegetable Consumption in Canadian Adolescents. J Am Diet Assoc. 2007;107(9):1511-1518.

27. McPhail D, Chapman G, Beagan BL. "I don’t really want to be sexist but-": Denying gender, reinscribing gender through food. under review. submitted.

28. Taylor N. Negotiating Popular Obesity Discourses in Adolescence: School Food, Personal Responsibility, and Gendered Food Consumption Behaviours. Food Culture and Society. 2011;14(4):587-606.

29. Wadsworth LA, McHugh TL, Thompson AM, et al. Dietary intake of Nova Scotia youth in grades 7 and 11. Can J Diet Pract Res. 2012;73(1):14-20.

30. Kirkpatrick S, Tarasuk V. Food insecurity is associated with nutrient inadequacies among Canadian adults and adolescents. J Nutr. 2008;138(3):604-612.

31. Mark S, Lambert M, O'Loughlin J, Gray-Donald K. Household Income, Food Insecurity and Nutrition in Canadian Youth. Can J Public Health. 2012;103(2):94-99. 
32. Widome R, Neumark-Sztainer D, Hannan P, Haines J, Story M. Eating When There is Not Enough to Eat: Eating Behaviors and Perceptions of Food Among Food-Insecure Youths. Am J Public Health. 2009;99(5):822-828.

33. Ahmadi N, Black JL, Velazquez CE, Chapman GE, Veenstra G. Associations between socio-economic status and school-day dietary intake in a sample of grade 5-8 students in Vancouver, Canada. Public Health Nutr. 7 2014:1-10.

34. Unger JB, Reynolds K, Shakib S, Spruijt-Metz D, Sun P, Johnson CA. Acculturation, physical activity, and fast-food consumption among Asian-American and Hispanic adolescents. J Community Health. 2004;29(6):467-481.

35. Black JL, Macinko J. Neighborhoods and obesity. Nutr Rev. 2008;66(1):2-20.

36. Morland K. Local Food Environments: Food Access in America. Boca Raton, FL: CRC Press, Taylor \& Francis Group; 2014.

37. Minaker LM, McCargar L, Lambraki I, et al. School region socio-economic status and geographic locale is associated with food behaviour of Ontario and Alberta adolescents. Can J Public Health. 2006;97(5):357-361.

38. Janssen I, Boyce W, Simpson K, Pickett W. Influence of individual- and area-level measures of socio-economic status on obesity, unhealthy eating, and physical inactivity in Canadian adolescents. Am J Clin Nutr. 2006;83:139-145.

39. Zenk SN, Powell LM. US secondary schools and food outlets. Health Place. 2008;14(2):336-346.

40. Kestens Y, Daniel M. Social inequalities in food exposure around schools in an urban area. Am J Prev Med. 2010;39(1):33-40.

41. Black JL, Day M. Availability of Limited Service Food Outlets Surrounding Schools in British Columbia. Can J Public Health. 2012;103(4):255-259. 
42. Birnbaum AS, Lytle LA, Murray DM, Story M, Perry CL, Boutelle KN. Survey development for assessing correlates of young adolescents' eating. Am J Health Behav. 2002;26(4):284-295.

43. Hanning RM, Royall D, Toews JE, Blashill L, Wegener J, Driezen P. Web-based Food Behaviour Questionnaire: Validation with Grades Six to Eight Students. Can J Diet Pract Res. 2009;70(4):172-178.

44. Pawlak R, Malinauskas B. Predictors of intention to eat 2.5 cups of vegetables among ninth-grade students attending public high schools in eastern North Carolina. J Nutr Educ Behav. 2008;40(6):392-398.

45. Propel Centre for Population Health Impact. School Health Action Planning and Evaluation (SHAPES): Healthy eating student questionnaire. Waterloo, ON: Propel Centre for Population Health Impact, University of Waterloo. 2008.

46. Health Canada. Eating Well with Canada's Food Guide, http://www.hc-sc.gc.ca/fnan/food-guide-aliment/index-eng.php. Accessed February 27, 2013.

47. Laska MN, Hearst MO, Forsyth A, Pasch KE, Lytle L. Neighbourhood food environments: are they associated with adolescent dietary intake, food purchases and weight status? Public Health Nutr. 2010;13(11):1757-1763.

48. He M, Tucker P, Gilliland J, Irwin J, Larsen K, Hess P. The Influence of Local Food Environments on Adolescents’ Food Purchasing Behaviours. Int J Environ Res Publ Health. 2012;9:1458-1471.

49. Thomson MD, Hoffman-Goetz L. Defining and measuring acculturation: a systematic review of public health studies with Hispanic populations in the United States. Soc Sci Med. 2009;69(7):983-991.

50. Lopez-Class M, Castro FG, Ramirez AG. Conceptions of acculturation: a review and statement of critical issues. Soc Sci Med. 2011;72(9):1555-1562. 
51. Bush M. Canadian Community Health Survey, Cycle 2.2, Nutrition (2004): IncomeRelated Household Food Security in Canada. 2007.

52. Statistics Canada. Canadian Community Health Survey (CCHS) Cycle 2.2 Nutrition: Questionnaire. http://www.hc-sc.gc.ca/fn-an/surveill/nutrition/commun/index-eng.php. Accessed December 15, 2012.

53. Bickel G, Nord M, Price C, Hamilton W, Cook J. Guide to Measuring Household Food Security. http://www.fns.usda.gov/fsec/files/fsguide.pdf. Accessed December 15, 2012.

54. Darling H, Reeder A, McGee R, Williams S. Brief Report: Disposable income, and spending on fast food, alcohol, cigarettes, and gambling in New Zealand secondary school students. J Adolescence. 2006;29(5):837-843.

55. BC Ministry of Education: Analysis and Reporting Group. 2006 BC School-Level Census Attributes.

56. Van Burren S. Multiple imputation of discrete and continuous data by fully conditional specification Stat Methods Med Res. 2007;16(3):219-242.

57. Bowman S, Gortmaker S, Ebbeling C, Pereira M, Ludwig D. Effects of Fast-Food Consumption on Energy intake and Diet Quality Among Children in a National Household Survey. Pediatrics. 2004;113(1):112-118.

58. Evans AE, Springer AE, Evans MH, Ranjit N, Hoelscher DM. A Descriptive Study of Beverage Consumption among an Ethnically Diverse Sample of Public School Students in Texas. J Am Coll Nutr. 2010;29(4):387-396.

59. Health Canada. Estimated Energy Requirements. http://www.hc-sc.gc.ca/fn-an/food-guidealiment/basics-base/1_1_1-eng.php. Accessed September 5, 2013.

60. Neumark-Sztainer D, Hannan P. Weight-related behaviors among adolescent girls and boys: results from a national survey. Arch Pediat Adol Med. 2000;154(6):569-577. 
61. French SA, Perry CL, Leon GR, Fulkerson JA. Dieting behaviors and weight change history in female adolescents. Health Psychol. 1995;14(6):548-555.

62. Dachner N, Picciuto L, Kirkpatrick S, Tarasuk V. Food purchasing and food insecurity among low-income families in Toronto. Can J Diet Pract Res. 2010;71(3):e50-56.

63. Darmon N, Drewnowski A. Does social class predict diet quality? Am J Clin Nutr. 2008;87(5):1107-1117.

64. Unger J, Reynolds K, Shakib S, Spruijt-Metz D, Sun P, Johnson C. Acculturation, physical activity, and fast-food consumption among Asian-American and Hispanic Adolescents. $J$ Commun Health. 2004;29(6):467-481.

65. McPhail D, Chapman G, Beagan B. Too Much of that Stuff Can't be Good": Canadian Teenagers, Morality, and Fast Food Consumption. Soc Sci Med. 2011;73(2):301-307.

66. Smoyer-Tomic KE, Spence JC, Raine KD, et al. The association between neighborhood socioeconomic status and exposure to supermarkets and fast food outlets. Health Place. 2008;14(4):740-754.

67. Black JL, Day M. Availability of limited service food outlets surrounding schools in British Columbia. Can J Public Health. 2012;103(4):e255-259.

68. Lytle L, Seifert S, Greenstein J, McGovern P. How do children's eating patterns and food choice change over time? Results from a cohort study. Am J Health Promot. 2000;14:222228.

69. Bruening M, Eisenberg ME, MacLehose R, Nanney M, Story M, Neumark-Sztainer D. Relationship between Adolescents' and Their Friends' Eating Behaviors: Breakfast, Fruit, Vegetables, Whole-Grain, and Dairy Intake. J Acad Nutr Diet. 2012;112(10):1608-1613.

70. Story M, Neumark-Sztainer D, French S. Individual and environmental influences on adolescent eating behaviors. J Am Diet Assoc. 2002;102(3 Suppl):S40-51. 
71. City of Vancouver. Vancouver Food City Strategy.http://vancouver.ca/files/cov/vancouverfood-strategy-final.PDF.Accessed February 7, 2013.

72. Rojas A, Valley W, Mansfield B, Orrego E, Chapman GE, Harlap Y. Toward Food System Sustainability through School Food System Change: Think\&EatGreen@ School and the Making of a Community-University Research Alliance. Sustainability. 2011;3(5):763-788.

73. Burrows TL, Martin RJ, Collins CE. A systematic review of the validity of dietary assessment methods in children when compared with the method of doubly labeled water. J Am Diet Assoc. 2010;110(10):1501-1510.

74. Livingstone MB, Robson PJ. Measurement of dietary intake in children. Proc Nutr Soc. 2000;59(2):279-293.

75. Kolodziejczyk JK, Merchant G, Norman GJ. Reliability and validity of child/adolescent food frequency questionnaires that assess foods and/or food groups. J Pediatr Gastroenterol Nutr. 2012;55(1):4-13. 


\begin{tabular}{|c|c|c|c|c|}
\hline & $\begin{array}{l}\text { Combined } \\
\text { Sample }^{c}\end{array}$ & $\begin{array}{l}\text { Elementary } \\
\text { School Only }\end{array}$ & $\begin{array}{l}\text { Secondary School } \\
\text { Only }\end{array}$ & P-Value \\
\hline Sample Size, n (\%) & $950(100.0)$ & $710(74.7)$ & $240(25.3)$ & \\
\hline Age in years, mean (SD) & $12.5(0.85)$ & $12.1(0.68)$ & $13.4(0.51)$ & $<0.001$ \\
\hline \multicolumn{4}{|l|}{ Grade in School, n (\%) } & \multirow{5}{*}{$N / A^{d}$} \\
\hline Grade 5 & $13(1.4)$ & $13(1.8)$ & $0(0.0)$ & \\
\hline Grade 6 & $139(14.8)$ & $139(19.9)$ & $0(0.0)$ & \\
\hline Grade 7 & $546(58.2)$ & $546(78.0)$ & $0(0.0)$ & \\
\hline Grade 8 & $240(25.6)$ & $0(0.0)$ & $240(100.0)$ & \\
\hline \multicolumn{4}{|l|}{ Gender, n (\%) } & \multirow{3}{*}{0.02} \\
\hline Boys & $487(51.4)$ & $380(53.6)$ & $107(44.8)$ & \\
\hline Girls & $461(48.6)$ & $329(46.4)$ & $132(55.2)$ & \\
\hline \multicolumn{4}{|l|}{ Student Country of Birth, n (\%) } & \multirow{3}{*}{0.60} \\
\hline Canada & $683(75.6)$ & $504(75.1)$ & $179(76.8)$ & \\
\hline Other & $221(24.4)$ & $167(24.9)$ & $54(23.2)$ & \\
\hline \multicolumn{4}{|l|}{ Both Parents Country of Birth, n (\%) } & \multirow{3}{*}{0.90} \\
\hline Canada & $197(22.2)$ & $145(22.1)$ & $52(22.5)$ & \\
\hline Other & $690(77.8)$ & $511(77.9)$ & $197(77.5)$ & \\
\hline \multicolumn{4}{|l|}{ English Spoken at Home, n (\%) } & \multirow{3}{*}{0.04} \\
\hline$x_{0}$ & $634(66.7)$ & $461(65.0)$ & $173(72.8)$ & \\
\hline No & $316(33.3)$ & $249(35.1)$ & $67(28.0)$ & \\
\hline \multicolumn{4}{|c|}{\begin{tabular}{|l|l} 
Household Food Insecurity Status, n (\%) & \\
\end{tabular}} & \multirow{3}{*}{0.49} \\
\hline Food Insecure & $131(15.8)$ & $100(16.3)$ & $31(14.3)$ & \\
\hline Food Secure & $700(84.2)$ & $514(83.7)$ & $186(85.7)$ & \\
\hline \multicolumn{4}{|l|}{ Lunch from Home, n (\%) } & \multirow{3}{*}{0.49} \\
\hline Brought Daily & $395(42.1)$ & $299(42.7)$ & $96(40.1)$ & \\
\hline Brought less than Daily & $544(57.9)$ & $401(57.3)$ & $143(59.8)$ & \\
\hline \multicolumn{4}{|l|}{ Weekly Spending Money, n (\%) } & \multirow{5}{*}{$<0.01$} \\
\hline None & $89(14.1)$ & $70(15.6)$ & $19(10.6)$ & \\
\hline$>\$ 0.00$ to $\$ 10.00$ & $234(37.1)$ & $181(4.02)$ & $53(29.4)$ & \\
\hline$>\$ 10.00$ to $\$ 20.00$ & $146(23.2)$ & $99(22.0)$ & $47(26.1)$ & \\
\hline$>\$ 20.00$ & $161(25.6)$ & $100(22.2)$ & $61(46.0)$ & \\
\hline $\begin{array}{l}\text { School-level Median Family Income, } \\
\text { mean (SD) }\end{array}$ & $\begin{array}{l}\$ 60,396 \\
(\$ 11,744)\end{array}$ & $\begin{array}{l}\$ 58,880 \\
(\$ 11,446)\end{array}$ & $\begin{array}{l}\$ 65,118 \\
(\$ 11,361)\end{array}$ & $<0.001$ \\
\hline \multicolumn{5}{|l|}{ Daily School-Day Dietary Intake, $\mathrm{n}(\%)^{\mathrm{e}}$} \\
\hline Fast Food Items & $162(17.2)$ & $112(15.9)$ & $50(20.9)$ & 0.07 \\
\hline Sugar-Sweetened Beverages & $294(31.4)$ & $214(30.6)$ & $80(33.9)$ & 0.34 \\
\hline Minimally Nutritious Packaged Snacks & $192(20.3)$ & $139(19.6)$ & $53(22.1)$ & 0.41 \\
\hline Fruit & $467(49.6)$ & $344(48.9)$ & $123(51.5)$ & 0.50 \\
\hline Vegetables & $393(42.3)$ & $287(41.4)$ & $106(44.7)$ & 0.37 \\
\hline Whole Grains & $325(34.7)$ & $224(32.1)$ & $101(42.3)$ & $<0.01$ \\
\hline Low Fat Milk & $427(46.3)$ & $325(47.2)$ & $102(43.8)$ & 0.37 \\
\hline $\begin{array}{l}\text { Weekly Off-Campus Food Purchasing, } \mathrm{n} \\
(\%)\end{array}$ & $333(35.7)$ & $227(32.8)$ & $106(44.4)$ & $<0.01$ \\
\hline
\end{tabular}

${ }^{a}$ Socio-demographic characteristics included age, grade in school, gender, student country of birth, both parent/guardian country of birth, English spoken at home, household food insecurity status (food insecure/food secure), lunch from home, weekly spending money and median school income (in $\$ 10,000$ increments using a school's median income derived from median family income estimates pertaining to students' neighborhoods of residence using Census dissemination area values). 
${ }^{b}$ Data sources: Median school income was provided by the BC Ministry of Education and derived from the 2006 Canadian Census. All other variables were from the 2012 Individual Eating Assessment Tool (IEAT) Survey from the Food Practices on School Days Study.

${ }^{c}$ All recruited classes served grade 7 students. However, some Vancouver schools house "split classes" where students from grades 6 and occasionally 5 and 6 , share classrooms with $7^{\text {th }}$ grade students.

${ }^{\mathrm{d}}$ Not applicable

${ }^{\mathrm{c}}$ Daily school-day dietary outcomes were defined based on responses about the following food and beverage items: Fast Food Items: Pizza; hot dog; hamburger/cheeseburger; breaded/fried chicken or fish; French fries or fried potatoes; taco or nachos; frozen packaged dinner; Sugar-Sweetened Beverages: Fruit-flavoured drinks; regular pop or soft drinks; sugar-sweetened iced tea; sports drinks; energy drinks; slurpees, slushies, or snow cones; Minimally Nutritious Packaged Snacks: Salty packaged snacks; candy or chocolate bars; baked sweets; frozen desserts; Fruit: Fresh fruit (not including juice); frozen or canned fruit; dried fruit; Vegetables: Fresh vegetables (raw or cooked, not including French fries); frozen or canned vegetables; Whole Grains: Any whole grain products (e.g., whole grain bread, whole grain bagel, pita or tortilla, brown rice or whole grain pasta, oatmeal or shredded wheat were provided as examples); Low Fat Milk: $2 \%$ milk; $1 \%$ or skim milk; soy milk (plain). Intake was coded as daily if responses to questions in a given category summed to 5 times per week or more. 
Table 2. Associations between school type, intake of minimally nutritious foods and off-campus food purchasing at or en route to school of students from 20 elementary schools and 6 secondary schools in Vancouver, Canada. ${ }^{\mathrm{a} b}$

\begin{tabular}{|c|c|c|c|c|c|c|c|c|}
\hline \multirow{2}{*}{ Independent Variables } & \multicolumn{2}{|c|}{ Daily Fast Foods $\left(\mathrm{n}=828^{\mathrm{c}}\right)$} & \multicolumn{2}{|c|}{$\begin{array}{l}\text { Daily Sugar-Sweetened } \\
\text { Beverages }\left(n=822^{c}\right)\end{array}$} & \multicolumn{2}{|c|}{$\begin{array}{l}\text { Daily Packaged Snack } \\
\text { Foods }\left(n=832^{c}\right)\end{array}$} & \multicolumn{2}{|c|}{$\begin{array}{l}\text { Weekly Off-Campus Food } \\
\text { Purchasing }\left(\mathrm{n}=826^{\mathrm{c}}\right)\end{array}$} \\
\hline & OR & $95 \% \mathrm{CI}$ & OR & $95 \% \mathrm{CI}$ & OR & $95 \% \mathrm{CI}$ & OR & $95 \% \mathrm{CI}$ \\
\hline \multicolumn{9}{|l|}{ School Type } \\
\hline Elementary & 1.00 & --- & 1.00 & --- & 1.00 & --- & 1.00 & --- \\
\hline Secondary & 1.92 & $1.18,3.12^{* *}$ & 1.36 & $0.87,2.13$ & 1.60 & $1.05,2.45^{*}$ & 1.63 & $1.10,2.42 *$ \\
\hline \multicolumn{9}{|l|}{ Gender } \\
\hline Girls & 1.00 & --- & 1.00 & --- & 1.00 & --- & 1.00 & --- \\
\hline Boys & 1.99 & $1.32,2.99 * * *$ & 1.74 & $1.27,2.38^{* * *}$ & 1.25 & $0.87,1.79$ & 1.32 & $0.97,1.79$ \\
\hline \multicolumn{9}{|l|}{ Acculturation } \\
\hline High & 1.00 & --- & 1.00 & --- & 1.00 & --- & 1.00 & --- \\
\hline Medium & 1.76 & $0.91,3.43$ & 1.04 & $0.68,1.61$ & 0.68 & $0.42,1.09$ & 1.17 & $0.77,1.78$ \\
\hline Low & 6.17 & $2.84,13.39 * * *$ & 1.67 & $0.91,3.04$ & 1.54 & $0.81,2.92$ & 1.20 & $0.66,2.18$ \\
\hline \multicolumn{9}{|l|}{ Food Security Status } \\
\hline Food Secure & 1.00 & --- & 1.00 & --- & 1.00 & --- & 1.00 & --- \\
\hline Food Insecure & 1.83 & $1.07,3.14 *$ & 1.52 & $0.97,2.37$ & 1.03 & $0.58,1.84$ & 1.38 & $0.86,2.21$ \\
\hline \multicolumn{9}{|l|}{ Lunch from Home } \\
\hline Less than Daily & 1.00 & --- & 1.00 & $\begin{array}{c}-- \\
\end{array}$ & 1.00 & --- & 1.00 & --- \\
\hline Daily & 0.92 & $0.59,1.41$ & 0.97 & $0.69,1.35$ & 1.77 & $1.21,2.58^{* *}$ & 0.59 & $0.43,0.82 * *$ \\
\hline \multicolumn{9}{|l|}{ Weekly Spending Money } \\
\hline None & 1.00 & --- & 1.00 & --- & 1.00 & --- & 1.00 & --- \\
\hline$>\$ 0.00$ to $\$ 10.00$ & 1.35 & $0.57,3.24$ & 0.89 & $0.52,1.52$ & 0.91 & $0.44,1.87$ & 1.44 & $0.82,2.54$ \\
\hline$>\$ 10.00$ to $\$ 20.00$ & 2.16 & $0.84,5.56$ & 1.02 & $0.57,1.84$ & 1.40 & $0.66,2.97$ & 2.71 & $1.46,5.03^{* *}$ \\
\hline$>\$ 20.00$ & 2.73 & $1.17,6.34 *$ & 1.71 & $0.95,3.06$ & 1.27 & $0.61,2.62$ & 2.63 & $1.40,4.95 * *$ \\
\hline Median School Income $(\$ 10,000)$ & 0.75 & $0.62,0.91 *$ & 0.85 & $0.71,1.01$ & 0.79 & $0.67,0.94 * *$ & 0.89 & $0.77,1.04$ \\
\hline
\end{tabular}

${ }^{a}$ All models controlled for gender, acculturation (high=spoke English at home, born in Canada, with Canadian born parents/guardians, low=spoke another language at home, born outside Canada, and parents/guardians born outside Canada), food security status, lunch from home, weekly spending money and median school income (in $\$ 10,000$ increments using a school's median income derived from median family income estimates pertaining to students' neighborhoods of residence using Census dissemination area values)

${ }^{b}$ Data sources: Median school income was provided by the BC Ministry of Education and derived from the 2006 Canadian Census. All other variables were from the 2012 Individual Eating Assessment Tool (IEAT) Survey from the Food Practices on School Days Study.

'Sample size after multiple imputation: 835. Missing values on acculturation, food security status, lunch from home, and spending money were handled using multiple imputation by chained equations ( 10 multiply imputed datasets).

$* \mathrm{p}<0.05, * * \mathrm{p}<0.01, * * * \mathrm{p}<0.001$ 
Table 3. Associations between school type and intake of nutritious foods at or en route to school of students from 20 elementary and 6 secondary schools in Vancouver, Canada. ${ }^{\text {a,b }}$

\begin{tabular}{|c|c|c|c|c|c|c|c|c|}
\hline \multirow{2}{*}{\begin{tabular}{|l|} 
Independent Variables \\
\end{tabular}} & \multicolumn{2}{|c|}{ Daily Fruit $\left(\mathrm{n}=827^{\mathrm{c}}\right)$} & \multicolumn{2}{|c|}{ Daily Vegetables $\left(\mathrm{n}=819^{\mathrm{c}}\right)$} & \multicolumn{2}{|c|}{$\begin{array}{l}\text { Daily Whole Grains } \\
\qquad\left(\mathrm{n}=828^{\mathrm{c}}\right)\end{array}$} & \multicolumn{2}{|c|}{$\begin{array}{l}\text { Daily Low Fat Milk } \\
\qquad\left(\mathrm{n}=810^{\mathrm{c}}\right)\end{array}$} \\
\hline & OR & $95 \% \mathrm{CI}$ & OR & $95 \% \mathrm{CI}$ & OR & $95 \% \mathrm{CI}$ & OR & $95 \% \mathrm{CI}$ \\
\hline \multicolumn{9}{|l|}{ School Type } \\
\hline Elementary & 1.00 & --- & 1.00 & --- & 1.00 & --- & 1.00 & --- \\
\hline Secondary & 0.96 & $0.66,1.41$ & 1.04 & $0.69,1.57$ & 1.61 & $1.14,2.25^{* *}$ & 0.97 & $0.58,1.62$ \\
\hline \multicolumn{9}{|l|}{ Gender } \\
\hline Girls & 1.00 & $\begin{array}{c}-- \\
\end{array}$ & 1.00 & --- & 1.00 & --- & 1.00 & --- \\
\hline Boys & 1.04 & $0.79,1.38$ & 1.00 & $0.75,1.33$ & 1.09 & $0.81,1.47$ & 1.72 & $1.28,2.31 * * *$ \\
\hline \multicolumn{9}{|l|}{ Acculturation } \\
\hline High & 1.00 & --- & 1.00 & --- & 1.00 & --- & 1.00 & --- \\
\hline Medium & 1.16 & $0.78,1.71$ & 1.13 & $0.77,1.67$ & 1.30 & $0.86,1.95$ & 1.46 & $0.96,2.20$ \\
\hline Low & 1.06 & $0.61,1.86$ & 1.48 & $0.84,2.61$ & 1.27 & $0.72,2.25$ & 0.84 & $0.47,1.49$ \\
\hline \multicolumn{9}{|l|}{ Food Security Status } \\
\hline Food Secure & 1.00 & --- & 1.00 & --- & 1.00 & --- & 1.00 & --- \\
\hline Food Insecure & 0.82 & $0.53,1.26$ & 0.76 & $0.49,1.17$ & 1.08 & $0.71,1.65$ & 1.09 & $0.70,1.71$ \\
\hline \multicolumn{9}{|l|}{ Lunch from Home } \\
\hline Less than Daily & 1.00 & --- & 1.00 & --- & 1.00 & --- & 1.00 & $-\overline{---}$ \\
\hline Daily & 1.23 & $0.92,1.66$ & 1.35 & $1.00,1.83$ & 1.48 & $1.09,2.01 *$ & 1.02 & $0.74,1.41$ \\
\hline \multicolumn{9}{|l|}{ Weekly Spending Money } \\
\hline None & 1.00 & --- & 1.00 & --- & 1.00 & --- & 1.00 & --- \\
\hline$>\$ 0.00$ to $\$ 10.00$ & 0.96 & $0.58,1.60$ & 1.00 & $0.60,1.67$ & 0.70 & $0.43,1.13$ & 0.89 & $0.53,1.48$ \\
\hline$>\$ 10.00$ to $\$ 20.00$ & 1.10 & $0.63,1.92$ & 1.30 & $0.77,2.19$ & 0.83 & $0.50,1.39$ & 1.04 & $0.60,1.80$ \\
\hline$>\$ 20.00$ & 1.08 & $0.63,1.82$ & 1.22 & $0.72,2.05$ & 0.81 & $0.48,1.36$ & 0.86 & $0.49,1.48$ \\
\hline Median School Income $(\$ 10,000)$ & 1.14 & $0.98,1.31$ & 1.03 & $0.88,1.21$ & 0.96 & $0.83,1.10$ & 0.80 & $0.66,0.97^{*}$ \\
\hline
\end{tabular}

${ }^{a}$ All models controlled for gender, acculturation (high=spoke English at home, born in Canada, with Canadian born parents/guardians, low=spoke another language at home, born outside Canada, and parents/guardians born outside Canada), food security status, lunch from home, weekly spending money and median school income (in $\$ 10,000$ increments using a school's median income derived from median family income estimates pertaining to students' neighborhoods of residence using Census dissemination area values)

${ }^{b}$ Data sources: Median school income was provided by the BC Ministry of Education and derived from the 2006 Canadian Census. All other variables were from the 2012 Individual Eating Assessment Tool (IEAT) Survey from the Food Practices on School Days Study.

${ }^{\mathrm{c}}$ Sample size after multiple imputation: 835. Missing values on acculturation, food security status, lunch from home, and spending money were handled using multiple imputation by chained equations ( 10 multiply imputed datasets).

$* \mathrm{p}<0.05, * * \mathrm{p}<0.01, * * * \mathrm{p}<0.001$ 